eight to ten days, the ruling diamond (which must be selected and mounted with great care) has to trace a furrow several miles long on a surface as hard as steel, and often breaks down when the grating is half finished. The work cannot be continued with a new diamond, and must be rejected and a new grating begun.

Thirdly, the slightest yielding or lost motion in any of the parts-screw, nut, carriage, or grating-or of the mechanism for moving the ruling diamond, is at once evidenced by a corresponding defect in the grating. When, after weeks, or sometimes months, of preparation all seems in readiness to begin ruling, the diamond point gives way, and as much time may have to be spent in trying out a new diamond.

When the accumulation of difficulties seems to be insurmountable, a perfect grating is produced, the problem is considered solved, and the event celebrated with much rejoicing, only to find the next trial a failure. In fact, more time has been lost through such premature exhibitions of docility than in all the frank declarations of stubborn opposition!

One comes to regard the machine as having a personality-I had almost said a feminine personality-requiring humouring, coaxing, cajoling, even threatening! But finally one realises that the personality is that of an alert and skilful player in an intricate but fascinating game who will take immediate advantage of the mistakes of his opponent, who "springs" the most disconcerting sur. prises, who never leaves any result to chance, but who nevertheless plays fair, in strict accordance with the rules of the game. These rules he knows, and makes no allowance if you do not. When you learn them, and play accordingly, the game progresses as it should.

As an illustration of the measure of success attained in this work, I would direct attention to a recent comparison by Messrs. Gale and Lemon of the performance of a grating of $6 \frac{1}{2}$-inch ruled surface with that of the echelon, the Perot and Fabry interferometer, \&c. The test object is the green radiation from incandescent mercury vapour. The spectrum of this radiation had been supposed a simple line until the interferometer showed it to be made up of five or more components. The whole group occupies a space about one-fifteenth of that which separates the sodium lines.

The grating clearly separates six components, while the more recently devised instruments give from six to nine. Two of these components are at a distance apart of only $1 / 5^{\circ}$ of the distance between the sodium lines, and these are so widely separated by the grating that it would be possible to distinguish doublets of one-half to one-third this value, so that the actual resolving power is from 300,000 to $400,000-$ of the same order, therefore, as that of the echelon.

It may well be asked, why is it necessary to go any further? The same question was put some twenty years ago when Rowland first astonished the scientific world with resolving powers of 100,000 , and it was his belief that the width of the spectral lines themselves was so great that no further "resolution" was possible. But it has been abundantly shown that this estimate proved in error, and we now know that there are problems the solution of which depends on the use of resolving powers of at least a million, and others are in sight which will require ten million for their accurate solution, and it is safe to say that the supply will meet the demand.

To return to our comparison of the telescope and the spectroscope; while the progress of investigation of the stellar universe will be ever furthered by increased size and resolving power of the telescope, this is very seriously hampered by the turbulence of the many miles of atmosphere through which the observations must be made. But there is no corresponding limit to the effective power of spectroscopes, and the solution of the corresponding problems of the subatomic structures and motions of this ultramicroscopic universe may be confidently awaited in the near future.

The messages we receive from the depth of the stellar firmament or from the electric arcs of our laboratories, come they in a millionth of a second or in hundreds of light-years, are faithful records of events of profound NO. 2202, VOL. 88] significance to the race. They come to us in cypher-in a language we are only beginning to understand.

Our present duty is to make it possible to receive and to record such messages. When the time comes for a Kepler and a Newton to translate them we may expect marvels which will require the utmost powers of our intellect to grasp

\section{THE CARBONISATION OF COAL.'}

I.

BEFORE it is possible to explain the highly complex actions taking place in the destructive distillation of coal, it is important to have some definite idea of the nature of the raw material with which we have to deal; and although many attempts have been made to gain an insight into the composition of coal, the wide variations in its characteristics, the difficulties attending any attempt to separate its constituents, and the ease with which the products of its decomposition undergo secondary changes at the temperatures employed in breaking it up, have prevented any very satisfactory solution of the problem being arrived at.

The one thing generally admitted is that coal is the fossil remains of a vegetation that flourished in the carboniferous period of the world's history, and that it has passed through successive stages of checked decay; the action of time, temperature, and pressure, generally out of contact with air, resulting in the conversion of these into the tertiary coals (such as brown coals or lignites), and probably by a continuance of the action yielding eventually the true coal.

All the plants of which we have fossilised record in our coal measures consisted of sedges and reeds, tree ferns, club mosses or lycopodia, and trees akin to the pine; but in those prehistoric days the conditions of growth -warmth, moisture, and carbon dioxide-were such that these plants grew with a succulent freedom and rapidity unknown in latter days, and which rendered their tissues an easy prey to decay and fermentation-actions which left only the more resistant unchanged. The work of Morris, Carruthers, Fleming, and Huxley has shown us that the bituminous matter in coal is largely derived from the spores of fossil mosses akin to the lycopodia. If we take the club mosses of to-day, we find their spores give us the body known as lycopodium-a substance so resinous in its nature that it resists the action of water, and is used to coat pills, while the same resinous characteristics render it so inflammable that a little blown through a flame provides the theatrical world with its artificial lightning. Spores of this character, from the giant growths of the carboniferous period, together with the more resinous portion of plants akin to the pine, are the substances which have best resisted the actions taking place during the ages that have elapsed in the formation of coal.

Starting with the fibre of the original plants, we find two well-defined bodies-cellulose, as represented by cotton fibre, and lignose, as represented by jute fibre. In the former, the percentage of carbon is 44 , in the latter 47 -each giving distinctive reactions with dilute acids at $70^{\circ} \mathrm{C}$., with anilin sulphate, with Schultze solution, and with mixtures of sulphuric and nitric acids. In the cellular tissue, we find starch; and besides these bodies, there are present the extractive and mineral matters of the sap.

Among the extractive matter we find gums-such as those exuding from the acacia and cherry, but also present in the juice of many plants-mucilage, vegetable jelly (which gives many juices their power of gelatinising), resins, essential oils, and other well-defined bodies. With some forms of vegetation, the essential oils undergo oxidation and form resins; and these, being more resistant to change, accumulate in masses of decaying vegetable matter, so that large quantities of them are found in lignite beds in a fossilised, but little changed, state.

The changes in the carbohydrates and extractive matters depent largely upon the conditions of decay. Given moisture arid air, they become converted into carbon dioxide and water; check the decay by cutting off free access of

1 From a course of Cantor Lectures given at the Royal Society of Arts in November and December, Igrx, by Prof. Vivian B. Lewes. 
air, the action is slowed down, and the gases evolved are carbon dioxide and methane.

It is clear that in a mass of rotting vegetation undergoing checked decay, fermentation must play an important part; and Renault found, in an extensive series of researches upon peat, that the most important factor in the conversion of vegetable deposits into peat was fungi and bacterial ferments, which give rise to the production of ulmic compounds of the composition: Carbon 65.31 , hydrogen 3.85 , oxygen 30.84 . Mulder also, at an earlier period, found that bodies could be extracted from peat, to which he gave the name of humic and ulmic acids; and Einof, Proust, and Braconnot found that such bodies formed the chief portion of peat.

These humus bodies have also been frequently identified in the lignites and also in the true coals.

None of these bodies are probably definite compounds, and resemble the residues obtained by the action of dilute acids on sugar and starch. The evidence, however, seems to point to the presence in all bituminous forms of coal of degradation products of the original vegetation of a humus or ulmic character, and which is probably the portion carrying the nitrogen; and in round numbers the proportions of the carbon, hydrogen, and oxygen will be not far removed from: Carbon 62 per cent., hydrogen 5 per cent., oxygen 33 per cent.

It is also well known that tertiary coals, like the brown coal and lignite deposits, are rich in fossil gums and resins, derived from the extractive matter of the vegetation; and a number of these have been isolated and analysed; whilst it is evident that in coal there are resin bodies of this character approximating to the general composition: Carbon, 79 per cent. ; hydrogen, i I per cent. ; oxygen, ro per cent.

The amount of resin constituents in the original vegetation, and which concentrates itself in the coal, must play an important part in chemical changes taking place during the formation and ultimate composition of the coal; and it is clear that although the vegetation that flourished in the coal age was of a very different character from that of later periods, yet in all probability the variations in the extractive matters of the plants varied to much the same extent as in the flora of to-day. Thus some deposits would be formed from vegetation containing but little of the resin-forming constituents, while others would be rich in them. We know the wide differences there are in the physical characteristics of the lignites-sometimes more like wood than coal, at others black, shining, and with a conchoidal fracture; these variations in appearance being due to the conditions under which they have been formed and the amount of resin constituents present.

If we start with the humus and resin constituents as they exist in the peat deposits of to-day, the latter are present only to the extent of 5 to ro per cent.; but in the decaying vegetation of the carboniferous age, they were probably present in much larger quantities. The humus, unprotected by it, rapidly undergoes decomposition, with concentration of carbon and evolution of methane, carbon dioxide, and water. As the layers of deposit above the carbonising mass grow thicker, so probably the temperature rises. The ratio of resin constituents increasing in proportion binds together the mass, and so helps to protect the remaining humus; and with the lapse of centuries lignite is formed. If the amount of resin constituents has been small, or, owing to local circumstances, has not been distributed evenly throughout the mass, the lignite is loose in structure, and during the ensuing ages continues decomposing until, if the pressure has been great and the temperature high, nothing but the residual basis and trace of resin constituent are left in the form of steam coal or anthracite. Under other conditions they may remain mixed with the bituminous coal in a seam and form the "mother of coal."

If the percentage of resin bodies has been very high - as in a drifted deposit of spores from lycopodia--and the temperature has been high, the resin bodies may become semi-liquid, and, mingling with surrounding earthy deposits, will give such compounds as boghead cannel, the organic matter in which has the same composition as resin, while it yields 33 per cent. of ash. Some of the NO. 2202 , VOL. 88$]$ cannels, however, are simply very rich bituminous coals. When the temperature has been high enough, some of the resin constituents practically distil into the underlying clay, yielding some forms of shale.

Heat also may cause isomeric and other changes in the resin bodies, thus altering their behaviour towards solvents; while the effect of heat under pressure upon the resins is in some cases to decompose them, with formation of hydrocarbons, a long series of which were isolated by Renard-among them being both saturated and unsaturated groups, together with hydrocarbons containing oxygen. Hydrocarbons, like retene $\left(\mathrm{C}_{18} \mathrm{H}_{18}\right)$, have frequently been isolated; and this body is found in many lignites. Within the last few months, Pictet and Ramseyer have isolated hexahydrofluorene $\left(\mathrm{C}_{13} \mathrm{H}_{16}\right)$ and others of the hydroaromatic hydrocarbons from coal-bodies which are resolved into aromatic hydrocarbons and hydrogen on destructive distillation. Renard long ago isolated not only saturated hydrocarbons like pentane and hexane, but also hexahydrides or naphthenes isomeric with the ethylene series, from the resin oil obtained by distilling wood resin at a low temperature $\left(350^{\circ} \mathrm{C}\right.$.); among these hexahydrides being $\mathrm{C}_{7} \mathrm{H}_{14}, \mathrm{C}_{9} \mathrm{H}_{18}$, and $\mathrm{C}_{10} \mathrm{H}_{20^{\circ}}$. The presence of bodies of this character in low temperature coal tar is a further proof of the presence of the resin bodies in coal.

All these degradation products of the original vegetation are to be found in the bituminous coals, the residual body and humus forming the basis, which is luted together by the hydrocarbons and resins; and the characteristics of the various kinds of coal are dependent upon the proportions in which the four groups of the conglomerate are present. These constituents of the coal have their own characteristic products of decomposition when the coal is - subjected to carbonisation. The humus bodies during carbonisation yield a large proportion of the gaseous products, and under the influence of heat show no sign of melting, but begin to break up at about $300^{\circ} \mathrm{C}$. The decomposition becomes more rapid as the temperature rises. Water distils over in the early stages; the tar is thin and poor in quantity, and the gases up to $600^{\circ} \mathrm{C}$. consist of hydrogen, methane, and carbon dioxide, with smaller quantities of carbon monoxide and traces of other saturated hydrocarbons. The decomposition can be completed below $800^{\circ} \mathrm{C}$.; but if the temperature is run up to $1000^{\circ} \mathrm{C}$., the carbon dioxide is reduced in quantity by the action on it of the red-hot carbon. Carbon monoxide increases correspondingly, while hydrogen and methane are still evolved.

The decomposition of the humus is also largely affected by the rate of heating. If slowly heated, a large proportion of the oxygen is given off in combination with hydrogen as water vapour, while if quickly raised in temperature more combines with carbon to form carbon dioxide and monoxide. The residue shows no sign of caking, while, like the naturally formed residue-mother of coal--it requires a large proportion of cementing material to make the particles cohere. The resin bodies and hydrocarbons which form the cementing portion in the coal melt between $300^{\circ} \mathrm{C}$. and $320^{\circ} \mathrm{C}$.; and if a coarsely powdered sample of the coal becomes pasty or semi-fluid at this temperature, it is a strong inference that the coal will coke on carbonisation-a fact noted by Anderson, and which is very useful in practice as a rough test. About these temperatures, also, the resin bodies and hydrocarbons begin to decompose.

The resin bodies at low temperature yield saturated hydrocarbons, unsaturated, chiefly hexahydrides or naphthenes, together with some oxygenated compounds; while the hydrocarbons yield paraffins and liquid products-all these primary constituents undergoing further decompositions at slightly higher temperatures. The liquids so produced begin to distil out as tar vapours and hydrocarbon gases, and leave behind with the residurum pitch, which at $500^{\circ} \mathrm{C}$. forms a mass already well coked together if the residuum from the humus is not too large in quantity. The coke formed at this temperature is, however, soft; but if the heat be raised to $1000^{\circ} \mathrm{C}$. the pitch residue undergoes further decomposition, yielding gas and leaving carbon, which binds the mass into a hard coke.

It has been shown by Muck and other observers that it is not always the coal containing the largest amount of volatile matter that evolves gas most rapidly or is richest 
in hydrocarbons, and this naturally follows from the fact that the coals which have the highest oxygen percentage are mostly those giving high volatile matter. As these are rich in the humus bodies which yield most of the diluting gas and but little tar or rich hydrocarbon gases, they cannot give the high result of a coal in which the oxygen content is about io per cent. or rather lower, and which contains a large percentage of resin bodies.

Experience shows that the weathering of coal is a phenomenon which is dependent upon the absorption of oxygen from the air; and this weathering is fatal to the coking of some coals, the slacks of which are so susceptible to oxidation that a few days' or weeks' exposure destroys their coking power. Now the avidity of oxygen for some vegetable resins is well known; the rapidity with which copal will absorb oxygen from the air may be taken as an example. Common resin has itself been formed by the oxidation of turpentine, and countless ages under conditions tending to reduction may well have whetted anew the resinic appetite for oxygen. In any case, the resin bodies are the compound; present in the coal most likely to possess this property; and it is the chemical actions so caused which lead to slow combustion, and, when accelerated by any rise in the surrounding temperature, is capable of generating sufficient heat to lead to the spontaneous ignition of masses of broken coal large enough to prevent the escape of the heat as it is developed.

Coal exhibits, to a lesser extent, the same property of absorbing gases that charcoal does. The least absorbent will take up one and a quarter times its own volume of oxygen, while many bituminous coals will absorb more than three times their volume of the gas. This action, at first largely physical, presents the oxygen in a probably active condition to the resin bodies in the coal, and leads to the rapid "weathering" and destruction of the coking properties found with some kinds of coal.

Boudouard has shown that when coal is weathered humus bodies are produced, and the coking power is lessened or destroyed. In seven samples of various coals the humus constituents were increased by the oxidation, which seems to show that the action of the absorbed oxygen is to attack the resin compounds; and as we know that carbon dioxide and moisture are the chief products of the earlier stages of heating of masses of coal, it seems probable that the result is a conversion of resinic into humus bodies with evolution of these gases. It is this change that leads to the serious deterioration in the gas and tar made from coal which has been too long in store; while the fact that a cannel coal like boghead or a shale does not weather is partly due to its dense structure, and also, in the same way, is an indication that the resin bodies of which it is chiefly composed are of a different type-a fact borne out by their resistance to certain coal solvents which freely attack the ordinary resin matter.

It has been shown that the coals richest in resin bodies are the cannels, whilst those that contain most of the residues of the humus bodies and least of the resin constituents are the steam coal and anthracite, and between these extremes come the large class of bituminous coals.

Many classifications of coal have been suggested, some based on their chemical, some on their physical, and others on their coking properties. Of the latter, the most generally adopted is that suggested by Gruner, in which he tabulates bituminous coals into five classes. Although Schondorff, Muck, and others have shown that it is not applicable to all kinds of coal, still this criticism applies to all classifications that have been proposed.

\begin{tabular}{|c|c|c|c|c|c|}
\hline Dry & & & $\begin{array}{c}\text { Carbon } \\
75^{-80}\end{array}$ & $\begin{array}{c}\text { Hydrogen } \\
4^{\prime} 3^{-}-5 \cdot 5\end{array}$ & $\begin{array}{l}\text { Oxygen } \\
\text { r } 3^{\circ} 0-18 \cdot 5\end{array}$ \\
\hline 2. $\mathrm{Fa}$ & $\begin{array}{c}\text { Coke porous } \\
\text { brittle ... }\end{array}$ & & $80-85$ & $5 \cdot 0-5$ & I0 $0^{\circ}-13^{\circ} 2$ \\
\hline Sem & $\begin{array}{l}\text { ke, } \\
\text {.. }\end{array}$ & $\left.\begin{array}{r}\text { but } \\
\ldots .\end{array}\right\}$ & 84 & $5^{\circ} \mathrm{O}$ & \\
\hline & be & $\ldots$ & $89-9 \mathbf{I}$ & $4 \cdot 5-5 \cdot 5$ & $45^{-}$ \\
\hline $\begin{array}{l}\text { Lean coa's ar } \\
\text { anthracite }\end{array}$ & Non-coking & $\cdots$ & $90-93$ & $3^{\circ} 0-4 \cdot 3$ & $3^{\circ} 0-4$ \\
\hline
\end{tabular}

This arrangement shows not only the coking properties, but also the changes in composition which the coal undergoes, the concentration of carbon, and reduction in highly oxidised bodies. In the first class we have the dry coals, yielding large volumes of gas and liquid products on distillation; and these -as might be expected-most resemble NO. 2202, VOL. 88] the lignites, and share with them the property of noncoking or binding together of the residue on carbonisation. This is due to the fact that the humus-like bodies are still present in much larger quantities than the resinic compounds and hydrocarbons, and as on distillation they leave no binding material in the residue, the resinic bodies cannot supply enough to give more than a friable mass.

In the second class of coals, altered conditions of temperature, pressure, and time have led to further decompositions of the humus bodies, and the resinic constituents and hydrocarbons having increased in ratio by concentration, a point is reached at which coking takes place, although not of a really satisfactory character.

In the third class, the action has still continued with further concentration of the resin bodies, hydrocarbons, and residuum, with the result that the former bodies are so increased in comparison to the humus and residuum that a good coke results, although, for reasons that will be discussed when speaking of coking processes, it is rather too porous and bulky.

In the fourth class, the proportion of resin and hydrocarbon bodies has reached the right ratio as compared with the humus and residuum, and the best coking coal is obtained. Bituminous coals of the kind classified by Gruner may therefore be looked upon as an agglomerate of humus and the degradation products of these bodies down to carbon, luted and protected by resin bodies and their derivatives; steam coal and anthracite as the degradation products of humus which has nearly completed its decomposition owing to the small quantity of resin bodies in the original vegetation; cannel coal as consisting mainly of resin bodies, which, having been in a semi-fluid condition, have mingled with the earthy matter in contact with it, so obtaining the high ash found in many kinds.

In putting forward this theory as to the composition of coal, I wish it distinctly understood that by the terms " humus" or "resin" bodies I do not imply any one definite compound, but merely bodies of this characterthe humus bodies all containing a percentage of hydrogen from 5 per cent. downwards, while the resin bodies all contain a percentage of hydrogen above 5 per cent. If it is once admitted that coal is a conglomerate of the kind I have indicated, it explains all those obscure points which no other theory touches-such as why with two coals of almost identical composition and of high oxygen content one should be a coking and the other a non-coking coal, the reason being that in the one the high oxygen content is due to humus bodies, which will not coke owing to the low pitch-forming nature of the hydrocarbons, while with the other the oxygen is due to resin bodies, which are essential to good coking.

In 1898 Anderson and Roberts, as the result of a long research upon the chemical properties of Scotch coals, came to the conclusior that a considerable part of the organic matter in coal consists of a complex compound comparatively rich in nitrogen, and also containing sulphur, and that there is also present resinous material, while the remaining constituents are composed of degradation products of the original carbohydrates of the coal plants, a theory which in its essentials agrees very well with my views on the subject.

During the present year (I9II) Burgess and Wheeler have published the results of a series of experiments upon the distillation of coals at various temperatures which lead them to conclude that coal contains two types of compounds of different degrees of ease of decomposition. The more unstable decomposes below $750^{\circ} \mathrm{C}$., and yields on distillation the paraffin hydrocarbons and no hydrogen; the other decomposes only at or above $750^{\circ} \quad \mathrm{C}$., and yields hydrogen only, or possibly hydrogen and oxides of carbon. The latter they suppose to be a degradation product of cellulose; the former to be derived from the resins and gums from the coal plants. The authors consider that the difference between one coal and another is determined by the proportion in which these two types exist in the coal.

All the evidence that can be adduced shows that when a coal undergoes destructive distillation all the hydrocarbons, together with the resin and humus constituents, undergo decomposition at a temperature certainly well below $700^{\circ} \mathrm{C}$., and that as the liquid and gaseous products distil out they leave behind their less volatile residues as a pitch, which lutes together the carbon particles and forms soft 
coke; while as the temperature rises above $750^{\circ} \mathrm{C}$, the pitch residue decomposes, yielding hydrogen, carbon monoxide, and methane as gases, while the carbon residue from the pitch binds the residual mass into coke. It is this residual pitch that Burgess and Wheeler have mistaken for a primary constituent of coal.

It is clear, however, that (putting detail on one side until our knowledge has been broadened by experience) the answer to the question as to what is the composition of coal-whether the answer is derived from a consideration of the actions taking place during its formation and of the substances from which it was derived, or is obtained from analytical data, as was done by Anderson and Roberts, or from the products of distillation, as has been done by Burgess and Wheeler-must be that coal is a conglomerate of humus and its degradation products with the resinic bodies and their derivatives.

(In the second lecture of the series, Prof. Lewes traccd the alterations in the methods of carbonisation from Murdoch's pot stills to the latest forms of gas-making retorts, showing the reasons that led to the horizontal iron retort, its gradual replacement by fire-clay retorts, the introduction of the inclined retort, and the improvements in gas settings.)

Since 1893, when the advent of the incandescent mantle as a practical method of developing light began to do away with the necessity for gas of high illuminating value, so general became the adoption of the mantle that in 1900 applications began to be made in Parliament in various Gas Bills to reduce the standard of light for those companies whose previous average had been about I6 candles, it being felt that a I4-candle gas was better fitted for vielding light with the incandescent mantle, power in the gas engine, and for heating in gas stoves than higher qualities; and it also gave the possibility of economies in manufacture, which it was hoped might lead to lowering of the price of gas to a point at which it would better compete with fuel gas for power purposes.

During the last ten years there has been an amount of activity in attempts to alter the process of gas manufacture which has excceded any that has taken place since the first few years of its inception, and this new era may be considered to have started with the inauguration of the vertical retort, in which, by utilising a large oval fire-clay retort set on end with a slight taper from bottom to top, much larger charges could be used than had been possible with the horizontal or inclined retorts, and in which also gravity was utilised to the full for charging and discharging.

The vertical retort dates back to $18_{2} 8$, when it was first introduced by John Brunton, who, finding that the gas could not escape freely from the lower portions of the charge, and so created considerable pressure, put a perforated pipe in the centre of the charge to afford an easy way of escape. Nothing more was heard of the process, so it probably failed; but at later dates attempts of the same kind were made by Lowe and Kirkham and also by Scott.

After these early experiments nothing seems to have been done for sixty years until the summer of Ig03, when Settle and Padfield put up a vertical retort at Exeter and Dr. Bueb started experimenting on the subject in Germany.

Vertical retorts during the last few years have met with great success on the Continent, and their use has spread with the greatest rapidity.

In England it has been felt that, good as are the results obtained with the vertical retort working intermittently, i.e., by putting in a full charge of coal, carbonising and drawing, and then recharging in the same way as with the old form of retorts, great improvements could be effected by making the process continuous, as was first attempted by Settle, so approaching more nearly to uniform conditions of carbonisation. Vertical retorts on this principle have been devised by Messrs. Duckham and Woodall, and by Messrs. Glover and West, and they certainly show results which will lead to continuous carbonisation being one of the most important factors in the future of gas manufacture.

The economies to be derived from carbonisation in bulk NO. 2202, VOL. 88 have on the Continent led to still further advances in the size of the charge, and little more than three years ago chamber carbonisation was introduced at Munich, in which charges of 3 to 8 tons of coal can be dealt with at a time, and this method also has met with a large amount of success, a number of installations having been erected on the principles laid down by Ries, Koppers, and others.

Many observers felt that the old horizontal retort could be made to yield better results than had hitherto been obtained, and Mr. C. Carpenter, at the South Metropolitan Gas Company's works, found that great advantages may be obtained by packing the old horizontal retorts full of coal, as had been suggested by Kunath in 1885, instead of only partly filling then, this doing away with the large space that had always been left above the charge of carbonising coal, and so eliminating to a great extent the baling of the gases and contact with the heated crown of the retort, this giving a distinct advance in make and quality not only in the gas, but in the tar.

Whilst these changes in form have been taking place, improvements in the settings, gas fuel, and regenerative firing have made such strides that the temperatures employed are limited only by the nature of the refractory materials used, and the result of these higher temperatures with light charges is to largely increase the volume of the gas obtainable per ton of coal, but at the same time its illuminating value is reduced, and the tar is deteriorated, and it also gives rise to stoppage of ascension pipes and an increase in naphthalene troubles in the service.

When iron retorts were used, the temperatures that could be employed were limited by the softening point of the iron, and rarely rose above $800^{\circ} \mathrm{C}$., and although only 9000 cubic feet of gas were made per ton of coal, the gas was rich in heating and lighting value, and the tar excellent in quality. The advent of the fire-clay retort, as has been seen, enabled temperatures to be increased; and 10,000 cubic feet of gas was the general yield. With the introduction of regenerative firing, the volume of gas obtained rose to 11,000 cubic feet, whilst the more modern dev 1 lopments approach a vield of 13,000.

In all these changes the gas manager has been actuated by the desire to get the greatest volume of gas possible per ton of coal, and at the same time to do it with the greatest economy, and but little attention has been paid to the quality of the tar and coke, which have been looked upon as by-products. In point of fact, the tar, when temperatures were pressed to their highest in lightly charged horizontal retorts, became so poor and choked with naphthalene and free carbon as to be almost valueless.

The intrcduction of large masses of coal in carbonisation, for reasons which will be discussed fully later, has led to distinct improvements in this respect, and although there is no modern tar which approaches in value the product of the old iron retort, the improvement in many places of late has been very marked.

(The gradual growth of the coke-making industry was then dealt with from the Meiler heap to the modern coke recovery ovens.)

(To be continued.)

\section{UNIVERSITY AND EDUCATIONAL} INTELLIGENCE.

LONDON.-The following are among the courses that will be held in the Faculty of Science at University College during the present term :- "General and Geological Aspects of Palæobotany," by Dr. Marie Stopes, on Tuesdays at 4 p.m., beginning on January 16 ; "Instruments and Maps," by Mr. M. T. Ormsby, on Tuesdays at 4 p.m., beginning on January 23 ; "Vertebrate Palæontology," by Prof. J. P. Hill, on Tuesdays at 5 p.m., beginning on January 23. In connection with the Francis Galton Laboratory for National Eugenics, Prof. Karl Pearson will deliver two lectures on "Sir Francis Galton," on Tuesdays, January 30 and February 6 , at $8.30 \mathrm{p.m}$., to be followed on subsequent Tuesdays by a course of six lectures on "Some Problems of Eugenics."

We learn from the Revue Scientifique that M. Georges Leygues has just given 25,000 francs to the University of 